A N N A L E S Annales de Bretagne et des Pays de l'Ouest

\title{
Tranvouez Yvon (dir.), Religion(s) en Bretagne aujourd'hui
}

\section{Marcel Launay}

\section{(2) OpenEdition}

\section{Journals}

\section{Édition électronique}

URL : http://journals.openedition.org/abpo/3099

DOI : $10.4000 /$ abpo.3099

ISBN : 978-2-7535-4275-4

ISSN : 2108-6443

Éditeur

Presses universitaires de Rennes

Édition imprimée

Date de publication : 30 juin 2015

Pagination : 171-173

ISBN : 978-2-7535-4273-0

ISSN : 0399-0826

\section{Référence électronique}

Marcel Launay, «Tranvouez Yvon (dir.), Religion(s) en Bretagne aujourd'hui », Annales de Bretagne et des Pays de l'Ouest [En ligne], 122-2 | 2015, mis en ligne le 30 juin 2015, consulté le 21 avril 2019. URL : http://journals.openedition.org/abpo/3099

Ce document a été généré automatiquement le 21 avril 2019.

(c) Presses universitaires de Rennes 


\title{
Tranvouez Yvon (dir.), Religion(s) en Bretagne aujourd'hui
}

\author{
Marcel Launay
}

\section{RÉFÉRENCE}

TRAnVouez Yvon (dir.), Religion(s) en Bretagne aujourd'hui, Brest/Vannes, Centre de recherches bretonne et celtique/Université de Bretagne occidentale/Institut culturel de Bretagne, 2014, 280 p., $20 €$.

1 Après des études plus historiques, la section Religion de l'Institut culturel de Bretagne s'est associée au Centre de recherche bretonne et celtique pour nous proposer un tableau de la situation des religions à l'époque actuelle, et particulièrement du catholicisme dans les cinq départements de la Bretagne historique. Le constat général par rapport aux périodes précédentes est sans doute brutal, mais réaliste, et il incite à une analyse sans concession. $67 \%$ des Bretons se disent catholiques, mais avec seulement 5 à $6 \%$ de pratiquants une fois par mois soit 180000 à 200000 fidèles. Quant aux autres religions, elles représentent $0,9 \%$ d'appartenance pour le protestantisme, $0,3 \%$ pour le judaïsme et $0,2 \%$ pour les religions vraiment minoritaires comme l'islam ou le bouddhisme. $30 \%$ se déclarent sans aucune appartenance religieuse. L'enquête concerne plusieurs dossiers. Les trois premiers cherchent à suivre à la fois les voies de l'évidement du catholicisme et les formes de sa reconfiguration, qu'il s'agisse de ses usages, de son organisation ou de ses diverses sensibilités. La quatrième traite des autres religions minoritaires et le dernier tente de montrer, à partir d'exemples significatifs, comment la religion se recompose sur la scène publique.

2 André Rousseau nous présente d'abord un portrait de ces catholiques majoritaires, mais en voie de marginalisation en tenant compte de l'incertitude de certaines statistiques. Ceux-ci, dans une position encore dominante mais nettement érodée par rapport aux époques de chrétienté, souffrent d'un recul de l'encadrement clérical avec la chute des vocations (1,6 prêtre en activité pour 10000 habitants). L'auteur de l'étude envisage alors 
à l'horizon 2030 plusieurs scénarios possibles. Qu'en est-il des rites traditionnels (Marcel Rivallain)? Avec une accélération après 2000, la baisse du nombre des baptêmes et des mariages, même si l'on retient les baptêmes d'adultes, est évidente. Les obsèques ont mieux résisté. Le catholicisme festif, quant à lui, (Joël Hascoët) est toujours vivace avec les pratiques liées aux pardons, pèlerinages et autres dévotions. Mais il n'est pas toujours possible de distinguer ce qui relève du culturel et d'une véritable religiosité, avec une attitude du clergé parfois ambivalente. L'institution catholique est en mutation, ce qui se traduit par une déclergification et une laïcisation du personnel diocésain (Laurent Laot). Ceci se vérifie avec le nombre de laïcs en mission ecclésiale pour divers services (275 pour le diocèse de Rennes par exemple) notamment pour la catéchèse ou la célébration des obsèques, même si le diaconat permanent est en progression. Les congrégations religieuses n'échappent pas à la baisse régulière de leurs effectifs. Pour les hommes, les Frères de Ploërmel (Louis Elégoët) passent de 576 présents en Bretagne en 1980 à 164 en 2010. Il en va de même pour les Filles de Jésus dites de Kermaria (Suzanne Le Rouzic) avec 1812 religieuses en 1994 et 1090 en 2011

3 L'enseignement catholique demeure-t-il fidèle à son caractère propre? (Laurent Laot). Si le nombre des établissements (1594 en 2013) demeure stable, on note un écart grandissant entre l'affichage de l'étiquette catholique et la réalité vécue au quotidien, preuve d'une déconfessionnalisation continue dans le corps enseignant. Le militantisme traditionnel des mouvements d'Action catholique (Jean Miossec) connaît lui aussi une chute spectaculaire de ses effectifs, ainsi dans le Finistère pour la JOC, même si l'ACO semble mieux résister (34 équipes en 2010 pour la Fédération brestoise).

Par contre, on assiste depuis 1971 à l'essor du Renouveau charismatique et des communautés nouvelles (René Gouriou). On compte 90 groupes de prière en Bretagne, en particulier dans le cadre urbain mais pas seulement, comme les Béatitudes, l'Emmanuel, le Chemin neuf, etc. Les catholiques « réformateurs " (Michel Bloch-Le Moine) se veulent en marge de l'institution, contestant ses orientations pastorales. À partir des années 1980, se développe une nébuleuse assez mouvante avec les communautés de base, l'Association culturelle de Boquen, les réseaux du Parvis, le réseau Jonas, etc., les groupes se faisant et se défaisant, croissant ou décroissant.

5 Pour les autres religions vient en tête le protestantisme (Jean-Yves Carluer) avec les anglicans, les membres de l'Église protestante unie de France et les évangéliques en progression. Au total, on relève environ 110 communautés locales, 150 lieux de culte et peut-être 15000 membres. L'islam est le nouveau venu, lié à l'immigration majoritairement issue du Maghreb avec une multitude de pratiques et de mouvances en tenant compte des musulmans dits sociologiques et ceux qui pratiquent (de 5 à $10 \%$ hormis le Ramadan), environ 15000 avec 42 lieux de culte essentiellement urbains. Le bouddhisme, sous ses diverses formes (Molly Chatalic) attire des pratiquants et des sympathisants, environ 2300 pratiquants dont 1500 d'origine asiatique. Parmi les autres religions très minoritaires on retrouve les Témoins de Jéhovah ou les Mormons très actifs.

6 Si les églises se vident, par contre l'accueil dans les monastères et les centres spirituels connaît pour des raisons très diverses, religieuses ou autres, un beau succès (Suzanne Le Rouzic). Le cas du Morbihan, avec le centre de Penboc'h, les abbayes de Timadeuc, Kergonan ou Campénéac, est particulièrement probant. Le patrimoine religieux, églises, chapelles très important en Bretagne (Yann Celton) est l'objet d'une demande de médiation culturelle multiforme avec la nécessité aux yeux des responsables 
ecclésiastiques de respecter certains critères spécifiques de ces édifices dont la sauvegarde n'est plus toujours assurée. La presse locale s'intéresse-t-elle encore au fait religieux (Marie-Thérèse Cloître)? Le Télégramme de Brest le prend en considération, même s'il reste relativement secondaire dans ses colonnes. En tout cas, le temps du journal catholique est révolu. Quant au rayon des librairies (André Rousseau) les religions n'y font plus recette alors que, signe des temps, l'ésotérisme se porte bien. De tous ces indicateurs, on peut conclure avec Yvon Tranvouez qu'est désormais brisé le miroir enchanté de la Bretagne catholique. Cependant le catholicisme, malgré ses faiblesses demeure une structure de sociabilité sans équivalent, mais avec une reconfiguration dans l'espace et peut-être aussi dans sa composition sociale sans qu'en bénéficient vraiment les autres religions. On regrettera que l'enquête sur l'intégrisme n'ait pu être menée à bien faute de répondants. Mais on ne pourra plus désormais faire l'impasse sur les Bretons sans religion alors que, sans doute, demeure la permanence d'un sacré non religieux. 